\title{
FOREWORD
}

\section{SALUTOGENESIS, THE FOCUS OF MUSIC AND YOGA THERAPIES}

Mother Teresa had stated that "anti-war" posturing is not the same as "pro-peace" initiatives. Similarly, the WHO has clearly stated that "mere absence of disease is not Health". With so much of stress on learning pathogenesis and pathology during their studies, the healthcare professionals are often unaware of the concept of Salutogenesis, which deals with promoting wellness.

Salutogenesis was first described by Aaron Antonovsky, a Medical Sociologist. He coined this term in 1968 to capture the concept of wellness, which he demonstrated among some of his subjects even under extremely adverse circumstances.

Medical science based on Pathogenesis looks at the following: causation of diseases; avoiding problems, such as disease and illness, which are abnormal states; reactive in nature with its focus on prevention and management of diseases; mitigation of pain and adverse squeal; works to keep the population alive.

Salutogenesis, on the other hand, looks at the following: what causes health and wellness; how to reach one's full potential for 'joy of Life' despite human-life that is inherently flawed and prone to illness and disease; be proactive to promote wellness for personal gain and growth; discover ways and means of living one's life fully, despite illness and disease.

Aaron Antonovsky showed that relatively unstressed people had much more resistance to illness than those who were highly stressed. Similarly, by de-stressing the individual, Yoga therapy and Music therapy operate through mind-body connections to promote wellness. Currently, research is ongoing to study the various epigenetic mechanisms initiated by these complementary and alternate therapies (CAM), which promote wellness and resistance to Life's adversities. Such evidence from cell biology could provide us the rationale for incorporate CAM along with modern medical management to create "optimal healing environment".

The twenty first Century will witness major evidence-informed adoption of integrative therapies that promote optimal healing and wellness.

- Prof KR Sethuraman, VC, SBVU. 